\title{
The SAKK cancer-specific geriatric assessment (C-SGA): a pilot study of a brief tool for clinical decision-making in older cancer patients
}

Kerri M Clough-Gorr ${ }^{1,2^{*}}$, Lea Noti ${ }^{3}$, Peter Brauchli ${ }^{4}$, Richard Cathomas ${ }^{5}$, Marius R Fried ${ }^{6,7}$, Gillian Roberts ${ }^{5}$, Andreas E Stuck ${ }^{3}$, Felicitas Hitz ${ }^{6+}$ and Ulrich Mey ${ }^{5+}$

\begin{abstract}
Background: Recommendations from international task forces on geriatric assessment emphasize the need for research including validation of cancer-specific geriatric assessment (C-SGA) tools in oncological settings. This study was to evaluate the feasibility of the SAKK Cancer-Specific Geriatric Assessment (C-SGA) in clinical practice.

Methods: A cross sectional study of cancer patients $\geq 65$ years old $(N=51)$ with pathologically confirmed cancer presenting for initiation of chemotherapy treatment (07/01/2009-03/31/2011) at two oncology departments in Swiss canton hospitals: Kantonsspital Graubünden (KSGR N=25), Kantonsspital St. Gallen (KSSG $N=26)$. Data was collected using three instruments, the SAKK C-SGA plus physician and patient evaluation forms. The SAKK C-SGA includes six measures covering five geriatric assessment domains (comorbidity, function, psychosocial, nutrition, cognition) using a mix of medical record abstraction (MRA) and patient interview. Five individual domains and one overall SAKK C-SGA score were calculated and dichotomized as below/above literature-based cut-offs. The SAKK C-SGA was evaluated by: patient and physician estimated time to complete, ease of completing, and difficult or unanswered questions.

Results: Time to complete the patient questionnaire was considered acceptable by almost all ( $\geq 96 \%)$ patients and physicians. Patients reported slightly shorter times to complete the questionnaire than physicians $(17.33 \pm 7.34$ vs. $20.59 \pm 6.53$ minutes, $p=0.02)$. Both groups rated the patient questionnaire as easy/fairly easy to complete ( $91 \%$ vs. $84 \%$ respectively, $p=0.14$ ) with few difficult or unanswered questions. The MRA took on average $8.32 \pm 4.72$ minutes to complete. Physicians (100\%) considered time to complete MRA acceptable, $96 \%$ rated it as easy/fairly easy to complete. Individual study site populations differed on health-related characteristics (excellent/good physician-rated general health KSGR 71\% vs. KSSG 32\%, $p=0.007$ ). The overall mean C-SGA score was $2.4 \pm 1.12$. Patients at KSGR had lower C-SGA scores ( $2.00 \pm 1.19$ vs. $2.81 \pm 0.90$, $\mathrm{p}=0.009)$ and a smaller proportion $(28 \% \mathrm{vs.65 \%}, \mathrm{p}=0.008)$ was above the C-SGA cut-off score compared to KSSG.

(Continued on next page)
\end{abstract}

\footnotetext{
* Correspondence: kclough@ispm.unibe.ch

${ }^{\dagger}$ Equal contributors

${ }^{1}$ Institute of Social and Preventive Medicine (ISPM), University of Bern,

Finkenhubelweg 11, Bern CH-3012, Switzerland

${ }^{2}$ Section of Geriatrics, Boston University School of Medicine, Boston Medical

Center, Boston, MA, USA

Full list of author information is available at the end of the article
} 
(Continued from previous page)

Conclusions: These results suggest the SAKK C-SGA is a feasible practical tool for use in clinical practice. It demonstrated discriminative ability based on objective geriatric assessment measures, but additional investigations on use for clinical decision-making are warranted. The SAKK C-SGA also provides important usable domain information for intervention to optimize outcomes in older cancer patients.

Keywords: Assessment, Cancer-specific geriatric assessment, Decision-making, Geriatric assessment, Older cancer patients, Older adults

\section{Background}

Cancer is considered an age-related disease of increasing public health concern due to worldwide aging populations. The World Health Organization (WHO) reports a projected continued rise in cancer mortality with an estimated 13.1 million cancer deaths worldwide in 2030 [1]. The majority of cancer patients presenting for cancer treatment are older ( $>65$ years old). Older cancer patients are often diagnosed at later stages, undertreated, and rarely included in clinical trials $[2,3]$. In fact, evidence on cancer treatment is mainly generated in younger cancer patients. Because aging is an individualized process older cancer patients represent a heterogeneous group requiring specific management-an oncological and research challenge $[2,4]$.

Comprehensive multidimensional geriatric assessment has been shown in general population studies to be a promising tool of assessment domains that capture a range of patient factors resulting in an individualized intervention-plan for optimizing clinical management and health outcomes [5-7]. Similarly, cancer-specific geriatric assessment (C-SGA) with multiple assessment domains can aid in identifying, managing and potentially correcting (through intervention) problems that might specifically interfere with cancer treatment [8,9]. For over a decade C-SGA has been a growing field of cancer-related research. Much of the earlier literature only allowed for analysis of indirect evidence and clinical opinion supporting the use of C-SGA [10]. More recent publications include a range of study designs as well as reviews that have expanded C-SGA specific knowledge. (for example [11-15]) Moreover, recommendations from the International Society of Geriatric Oncology (SIOG) task force on geriatric assessment and the European Organization for Research and Treatment of Cancer (EORTC) Elderly Task Force have underscored the need for additional research including validation of C-SGA tools in oncological settings. [16,17] Despite growing evidence additional studies to determine C-SGA's ability to predict relevant outcomes such as choice of treatment, treatment tolerance, treatment completion, survival, quality of life, and comparative effectiveness to physician judgment are still needed [13,16,18-24]. Incorporating C-SGA into clinical trials of older cancer patients could provide such evidence, establish an objective measure for inclusion into clinical trials, and further advance the knowledgebase accelerating translation of use into evidence-based practice. Evidence from use of C-SGA in clinical trial settings has been increasing but does not directly inform on feasibility of implementation in daily oncological practice [24-26]. In clinical practice the ease and time to perform a C-SGA is a vital to whether or not it will be adopted in regular practice and requires specific investigation.

The Swiss Group for Clinical Cancer Research (Schweizerische Arbeitsgemeinschaft für Klinische Krebsforschung [SAKK]) developed the SAKK C-SGA specifically for use in clinical trials including older cancer patients as well as daily oncological practice. The SAKK C-SGA includes six standard geriatric assessment measures covering five geriatric assessment domains (comorbidity, function, psychosocial, nutrition, and cognition) using a mix of medical record abstraction (MRA) and patient interview (described in Table 1). The individual measures are brief, reliable, valid, and predictive of morbidity and mortality in geriatric patients [27-33]. The measures have been well studied in the geriatric-oncology and geriatric assessment literature [34]. The SAKK C-SGA was developed based on an extensive literature search and expert clinical advice to be brief and easy to implement in busy clinical settings (i.e. low physician and patient burden appropriate for clinical practice as well as clinical trials). The patient questionnaire alone was previously pilot tested in a small sample $(\mathrm{N}=5)$ of older cancer patients to judge phrasing and comprehension in older adults, but the complete SAKK C-SGA has not been assessed for ease of administration in daily oncological settings. To address this gap the aim of the current study was to evaluate feasibility and practical use of the SAKK C-SGA in Swiss clinical practices caring for older cancer patients.

\section{Methods}

The protocol for this study was reviewed and approved by the Kantonsspital Graubünden (KSGR) Institutional Review Board (IRB) Ethics Committee and the Kantonsspital St. Gallen (KSSG) IRB Ethics 
Table 1 Content and operationalization of the SAKK cancer-specific geriatric assessment (C-SGA)

\begin{tabular}{|c|c|c|c|c|c|}
\hline $\begin{array}{l}\text { Assessment } \\
\text { domain }\end{array}$ & Assessment tool & $\begin{array}{l}\text { Number of } \\
\text { questions }\end{array}$ & How administered & $\begin{array}{l}\text { Estimated time } \\
\text { required }(\mathrm{min})\end{array}$ & Range: cut-off \\
\hline \multicolumn{6}{|c|}{ Individual domains } \\
\hline Comorbidity & $\begin{array}{l}\text { Age-adjusted Charlson Comorbidity } \\
\text { Index (CCI)[27, 28] }\end{array}$ & 18 & $\begin{array}{l}\text { Medical Record } \\
\text { Abstraction (MRA) }\end{array}$ & $5-10$ & $0-43: \geq 4$ \\
\hline Function & Vulnerable Elders Survey (VES-13) [29] & 12 & $\begin{array}{l}\text { Self-report or Interviewer } \\
\text { Administered }\end{array}$ & $<5$ & $0-10: \geq 3$ \\
\hline \multirow[t]{2}{*}{ Psychosocial } & $\begin{array}{l}\text { Geriatric Depression Scale 5-item short } \\
\text { form (GDS-5) [30] }\end{array}$ & 5 & Self-report or Interviewer & $<5$ & $0-5: \geq 2$ \\
\hline & $\begin{array}{l}\text { Modified MOS- Social Support Survey } \\
\text { (mMOS-SS) [33] }\end{array}$ & 8 & Administered & $<5$ & $0-8: \leq 2.5$ \\
\hline Nutrition & Mini Nutritional Assessment (MNA) [31] & 3 & $\begin{array}{l}\text { Interviewer administered } \\
\text { and MRA }\end{array}$ & $<4$ & $0-14: \leq 11$ \\
\hline Cognition & Mini-Cog [32] & 3 & Interviewer administered & 5 & $\begin{array}{l}\text { 1-3 w/clock draw: } 0 \text { or } 1-2 \\
\text { w/abnormal clock }\end{array}$ \\
\hline \multicolumn{6}{|l|}{ SAKK C-SGA } \\
\hline 5 Domains & $\begin{array}{l}\text { Six Measures: CCI, VES-13, GDS-5, } \\
\text { mMOS-SS, MNA, Mini-Cog }\end{array}$ & $\begin{array}{l}\text { 22- Patient } \\
\text { 20- MRA }\end{array}$ & $\begin{array}{l}\text { Self-report, Interviewer } \\
\text { Administered, MRA }\end{array}$ & $<30$ & $0-5: \geq 3$ \\
\hline
\end{tabular}

Committee. The study was conducted in compliance with all federal regulations governing the protection and privacy of human subjects, the Helsinki Declaration, and with the informed consent of the participants.

\section{Study population}

We conducted a cross sectional study of older cancer patients (total study population, $\mathrm{N}=51$ ) cared for at two oncology departments in canton hospitals in Switzerland: KSGR $(\mathrm{N}=25)$ and KSSG $(\mathrm{N}=26)$. The study population included a consecutive case series of older adults ( $\geq 65$ years old) with physician permission to participate, a pathologically confirmed cancer diagnosis (newly diagnosed or relapsed), presenting for initiation of a new chemotherapy treatment (first-line or subsequent treatment) between July 2009 and March 2011.

\section{Data collection}

Data for this study was collected using three instruments, the SAKK C-SGA plus physician and patient evaluation forms. The SAKK C-SGA (English, German, French, Italian) and scoring instructions (English only) are available by author request.

\section{SAKK C-SGA}

The SAKK C-SGA was administered in two parts by trained study personnel (hereafter referred to as physician) before the start of chemotherapy treatment. The interviewer-administered C-SGA patient questionnaire contained 22-questions with a variety of responses (e.g. rating scales, yes/no, word recall, clock drawing and spaces for recording the results of the MRA see Additional file 1). The C-SGA MRA included 20-questions for extracting health-related information (height, weight, comorbidities) from patient medical records.

\section{Patient and physician evaluation forms}

The patient evaluation form was filled-out by patients immediately after completion of the SAKK C-SGA patient interview. It had a total of 11-questions divided into two parts: (1) five patient information questions (gender, marital status, education, nationality, mother tongue); and (2) six questions relating to the patient questionnaire (estimated/acceptable time to complete, ease of administration, patient reaction, difficult/unanswered questions).

Personnel administering the SAKK C-SGA completed the physician evaluation immediately after each patient assessment. The physician questionnaire included 18questions divided into four sections: (1) six patient information questions (age, general health, type cancer, treatment approach, life expectancy, performance status); (2) six questions relating to the C-SGA patient questionnaire (estimated/acceptable time to complete, ease of administration, patient reaction, difficult/unanswered questions); (3) four questions relating to MRA (estimated time to complete, ease of conducting, difficulty of obtaining information, missing information), and (4) two questions relating to training (years of experience, type of training).

\section{Analytic variables}

\section{Socio-demographic characteristics}

We categorized information on age (65-69,70-79, 80+ years); gender (male, female); education (compulsoryup to 10th grade, secondary-high school, teacher training or vocational diploma; tertiary-undergraduate, graduate, post-graduate degree); marital status (single, 
married, widowed, divorced); and nationality (Swiss, other).

\section{Health-related characteristics}

Physician-rated general health was assessed by a single question with five answer likert scale ranging from "excellent" to "poor". We also classified information on type of cancer (bladder, breast, colon, leukemia, lung, lymphoma, pancreatic, prostate, uterine, other); type of treatment (curative, palliative), physician judgement of life expectancy ( $<1$ year, $1-2$ years, $3+$ years); and WHO performance score $(0-4)$ with higher scores indicating worse health [35].

\section{SAKK C-SGA}

Table 1 shows content and operationalization of the SAKK C-SGA and individual domain assesment tools. SAKK C-SGA scoring was calculated as five individual domain scores (function, psychosocial, nutrition, cognition, comorbidity based on the published scoring rules for individual measures) and one overall C-SGA score. All scores were based on whole number ranges. The five individual domain scores were dichotomized as deficit or not based on literature-based pre-determined cut-off scores for each measure (see Table 1). Individual domains with more than one measure (e.g. psychosocial) were considered to be a deficit if at least one measure crossed the cut-off. The overall C-SGA score was calculated by summing the number of individual domain deficits (range 0-5) and dichotomizing deficits as $\leq 2$ (fit for standard treatment) vs. $\geq 3$ (unfit for standard treatment) $[11,14]$.

\section{SAKK C-SGA evaluation}

The SAKK C-SGA was assessed by patient and physician estimated time to complete (mean time, acceptable yes/no), ease of completing (easy/fairly easy, just right, hard/very hard), patient reaction (interested, indifferent, rejecting), and difficult or unanswered questions (yes/no).

\section{Analytic methods}

We examined the descriptive characteristics in the total population and compared the distributions between study sites using Student's t-test for continuous variables and chi-square or Fisher's exact tests for categorical variables testing for statistical significance in their differences. Similar methods were applied to results from the patient and physician evaluations. Associations between C-SGA scores and healthrelated characteristics were assessed using Spearman correlations. All analyses were performed using SAS (V9.3 SAS Institute, Cary, NC) and all $\mathrm{p}$ values were from two-sided tests.

\section{Results}

\section{Population characteristics}

Table 2 shows the characteristics of the individual study site populations as well as total study population. Most of the study population was Swiss (88\%) and over half were aged 70-79 years, male with excellent/good physician-rated general health. Lung cancer $(20 \%)$ and lymphoma (25\%) were the most common types of cancers being treated in the total study population.

The individual study site populations were evenly distributed (KSGR 49\%, KSSG 51\%) but differed on health-related characteristics. KSGR had more patients with excellent/good $(71 \%$ vs. $32 \%, \mathrm{p}=0.007)$ physicianrated general health. The majority of KSSG patients were receiving palliative treatment $(88 \%$ vs. $52 \%$, $\mathrm{p}=0.006)$; had a life expectancy of $<1$ year $(61 \% v s$. $19 \%, \mathrm{p}=0.01)$; and a WHO performance score of 2 (50\% vs. $4 \%, \mathrm{p}=<0.001)$.

\section{Patient and physician evaluation of the SAKK C-SGA}

Table 3 displays the results of patient and physician evaluation of the SAKK C-SGA. The time to complete the patient questionnaire was considered acceptable by almost all patients and physicians. Patients reported slightly shorter times to complete the questionnaire than physicians $(17.33 \pm 7.34$ vs. $20.59 \pm 6.53$ minutes, $\mathrm{p}=0.02$ ). Both groups rated the SAKK C-SGA patient questionnaire as easy/fairly easy to complete $(91 \% v s$. $84 \%$ respectively, $\mathrm{p}=0.14$ ) with few difficult or unanswered questions. Physicians reported the MRA took on average $8.32 \pm 4.72$ minutes, $100 \%$ considered the time to complete acceptable with $96 \%$ rating it as easy/ fairly easy to complete. The majority of personnel administering the SAKK C-SGA were nursing staff with over 11 years of clinical experience (data not shown).

\section{C-SGA characteristics of the study population}

Table 4 describes the C-SGA characteristics of the study population. The overall mean C-SGA score was 2.4 \pm 1.12. Patients at KSGR had lower C-SGA scores (2.00 \pm 1.19 vs. $2.81 \pm 0.90, \mathrm{p}=0.009)$ and a smaller proportion ( $28 \%$ vs.65\%, p $=0.008)$ was above the C-SGA cut-off score compared to KSSG. In the total population the most common domain deficits were function, nutrition and comorbidity. By site population KSGR had statistically significantly fewer patients with a nutrition domain deficit than KSSG. C-SGA score was correlated with all health-related characteristics but not with age. Healthrelated characteristics differed by C-SGA cut-off scores. More patients with C-SGA score below the cut-off had excellent/good physician-rated general health (67\% vs. 32\%, $\mathrm{p}=0.007)$; were receiving curative treatment $(44 \%$ vs. $13 \%, \mathrm{p}=0.02)$; and had a WHO performance score of 0 or 1 ( $85 \%$ vs. $58 \%, \mathrm{p}=0.002)$. 
Table 2 Characteristics of the individual site and total study population

\begin{tabular}{|c|c|c|c|c|}
\hline & $\begin{array}{l}\text { KSGR } \\
N=25\end{array}$ & $\begin{array}{l}\text { KSSG } \\
N=26\end{array}$ & $\begin{array}{l}\text { Total population } \\
\qquad N=51\end{array}$ & \\
\hline Characteristic & & n ( & & \\
\hline \multicolumn{5}{|l|}{ Socio-demographic } \\
\hline \multicolumn{5}{|l|}{ Study site } \\
\hline KSGR & $25(100)$ & - & $25(49)$ & \\
\hline KSSG & - & $26(100)$ & $26(51)$ & \\
\hline \multicolumn{5}{|l|}{ Age } \\
\hline $65-69$ years & $6(24)$ & $7(27)$ & $13(25)$ & 0.57 \\
\hline 70-79 years & $15(60)$ & $12(46)$ & $27(53)$ & \\
\hline $80+$ years & $4(16)$ & $7(27)$ & $11(22)$ & \\
\hline \multicolumn{5}{|l|}{ Gender } \\
\hline Male & $17(68)$ & $11(42)$ & $28(55)$ & 0.07 \\
\hline Female & $8(32)$ & $15(58)$ & $23(45)$ & \\
\hline \multicolumn{5}{|l|}{ Education } \\
\hline Compulsory & $7(28)$ & $5(21)$ & $12(24)$ & 0.60 \\
\hline Secondary & $17(68)$ & $16(67)$ & $33(67)$ & \\
\hline Tertiary & $1(4)$ & $3(12)$ & $4(8.2)$ & \\
\hline \multicolumn{5}{|l|}{ Marital status } \\
\hline Single & $0(0)$ & $0(0)$ & $0(0)$ & $0.92^{\#}$ \\
\hline Married & $18(72)$ & $17(65)$ & $35(69)$ & \\
\hline Widowed & $7(28)$ & $7(27)$ & $14(27)$ & \\
\hline Divorced & $0(0)$ & $2(7.7)$ & $2(3.9)$ & \\
\hline \multicolumn{5}{|l|}{ Nationality } \\
\hline Swiss & $22(88)$ & $23(88)$ & $45(88)$ & 1.00 \\
\hline Other & $3(12)$ & $3(12)$ & $6(12)$ & \\
\hline \multicolumn{5}{|l|}{ Health-related } \\
\hline \multicolumn{5}{|c|}{ Physician-rated general health } \\
\hline Excellent/good & $17(71)$ & $8(32)$ & $25(51)$ & 0.007 \\
\hline Fair & $6(25)$ & $9(36)$ & $15(31)$ & \\
\hline Poor/very Poor & $1(4.1)$ & $8(32)$ & $9(18)$ & \\
\hline \multicolumn{5}{|l|}{ Type of cancer } \\
\hline Bladder & $1(4.0)$ & $0(0)$ & $1(1.9)$ & $0.40^{\#}$ \\
\hline Breast & $0(0)$ & $1(3.8)$ & $1(1.9)$ & \\
\hline Colon & $6(24)$ & $0(0)$ & $6(12)$ & \\
\hline Leukemia & $0(0)$ & $7(27)$ & $7(14)$ & \\
\hline Lung & $5(20)$ & $5(19)$ & $10(20)$ & \\
\hline Lymphoma & $5(20)$ & $8(31)$ & $13(25)$ & \\
\hline Pancreatic & $0(0)$ & $1(3.8)$ & $1(1.9)$ & \\
\hline Prostate & $3(12)$ & $1(3.8)$ & $4(7.8)$ & \\
\hline Uterine & $0(0)$ & $1(3.8)$ & $1(1.9)$ & \\
\hline Other & $5(20)$ & $2(7.7)$ & $7(14)$ & \\
\hline \multicolumn{5}{|l|}{ Type of treatment } \\
\hline Curative & $12(48)$ & $3(12)$ & $15(29)$ & 0.006 \\
\hline Palliative & $13(52)$ & $23(88)$ & $36(71)$ & \\
\hline
\end{tabular}


Table 2 Characteristics of the individual site and total study population (Continued)

\begin{tabular}{lccc}
\hline Life expectancy & & \\
$<1$ year & $4(19)$ & $16(61)$ & $20(42)$ \\
$1-2$ years & $8(38)$ & $6(23)$ & $14(30)$ \\
$3+$ years & $9(43)$ & $4(15)$ & $13(28)$ \\
WHO performance score & & & $19(37)$ \\
0 & $15(60)$ & $4(15)$ & $18(35)$ \\
1 & $9(36)$ & $9(35)$ & $14(27)$ \\
2 & $1(4.0)$ & $13(50)$ & $<0.001$ \\
\hline
\end{tabular}

KSGR Kantonsspital Graubünden, KSSG Kantonsspital St. Gallen, WHO World Health Organization.

* Test of difference between study sites.

\# Significance test excluding marital status single and cancers with zero cells.

Table 3 Patient and physician evaluation of SAKK cancer-specific geriatric assessment (C-SGA)

\section{Patient $N=51 \quad$ Physician $N=9$}

$\mathrm{n}(\%)$ or mean $\pm \mathrm{SD}$

$P$ value $^{*}$

\section{Patient questionnaire}

Estimated time to complete

Average time in minutes

Rated time as acceptable

\author{
$17.33 \pm 7.34$
}

$44(96)$

$42(91)$

$4(8.7)$

$0(0)$

$37(73)$

$7(14)$

$0(0)$

$5(11)$

39 (89)

$6(14)$

38 (86)

No

\section{Medical record abstraction}

Estimated time to complete

Average time in minutes

Rated time as acceptable

Ease of completing

$\begin{array}{lcc}\text { Easy/fairly easy } & - & 47(96) \\ \text { Just right } & - & 2(4.1) \\ \text { Hard/very hard } & - & 0(0)\end{array}$

C-SGA Cancer-Specific Geriatric Assessment; SD standard deviation.

* Test of difference between patients and physicians.

\# Significance test based on two categories created by collapsing the bottom two categories with the smallest cell counts into one (e.g. Easy/Fairly easy vs. Just right/Hard/Very hard).

${ }^{\S}$ Significance test not possible due to zero cells.
$20.59 \pm 6.53 \quad 0.02$

$51(100)-0.22$

$43(84) \quad 0.14^{\#}$

$3(5.9)$

$5(9.8)$

44 (86)

$5(9.8)$

2 (3.9)

8 (16)

0.91

11 (22)

0.03

40 (78)

$8.32 \pm 4.72$

50(100)

$\begin{array}{lr}- & 8.32 \pm 4.72 \\ - & 50(100)\end{array}$

(96)

$0(0)$ 
Table 4 Cancer-specific geriatric assessment (C-SGA) characteristics in the individual site and total study populations C-SGA characteristics by study site and total population

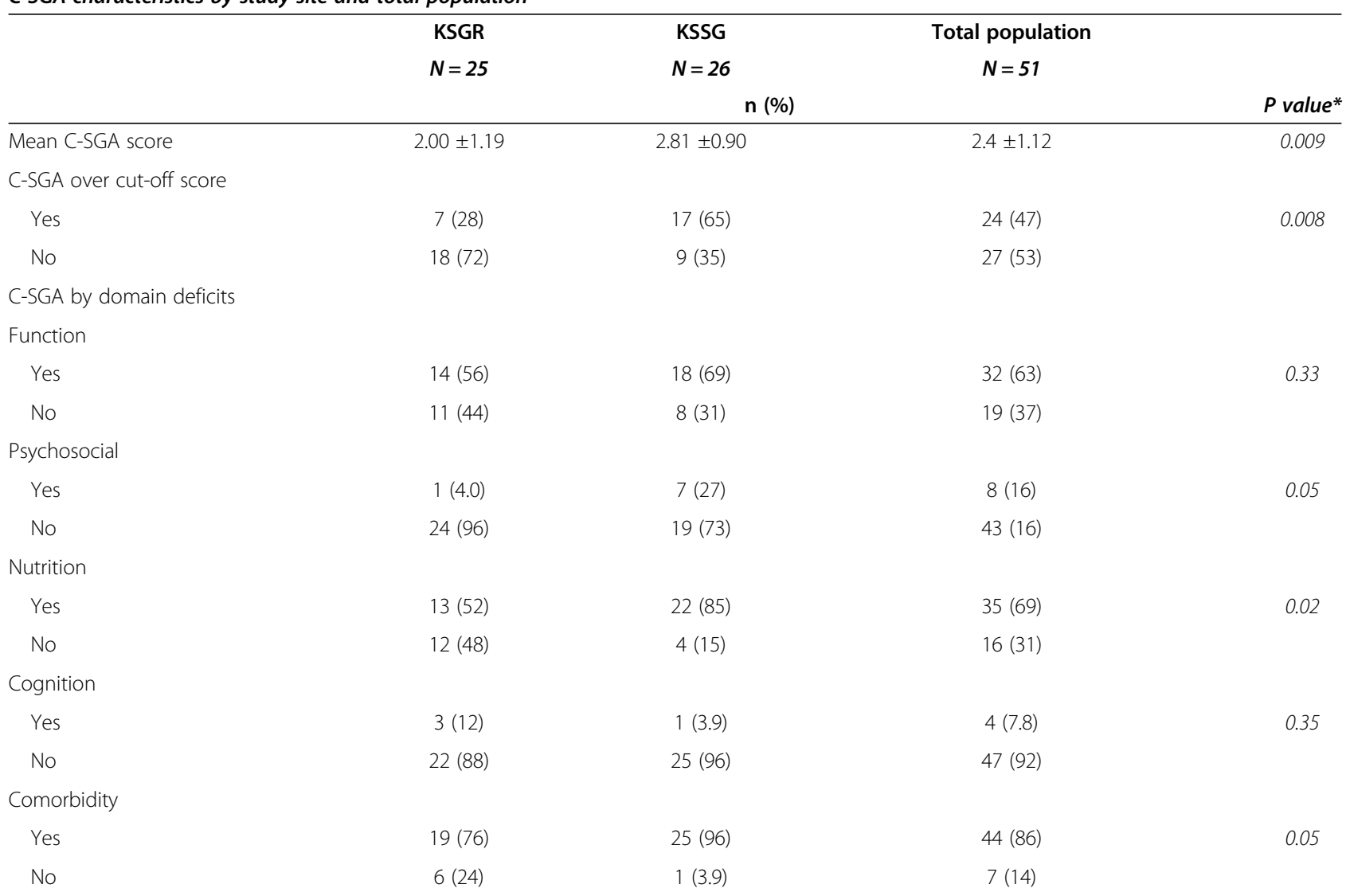

C-SGA association with health-related characteristics

$\begin{array}{lc} & \text { Correlation coefficient } \\ \text { Age } & 0.12 \\ \text { Physician-rated general health } & 0.39 \\ \text { Type of treatment } & -0.38 \\ \text { Life expectancy } & -0.32 \\ \text { WHO performance score } & 0.63 \\ \text { Health-related characteristics by C-SGA cut-off score } & \end{array}$

$$
\begin{gathered}
P \text { value } \\
0.43 \\
0.008 \\
0.01 \\
0.03 \\
<0.0001
\end{gathered}
$$

Health-related characteristics by C-SGA cut-off score

Below C-SGA cut-off score

$N=27$

n (\%)
Above C-SGA cut-off score

$$
N=24
$$

Age

$$
\begin{aligned}
& \text { 65-69 years } \\
& 70-79 \text { years } \\
& 80+\text { years }
\end{aligned}
$$$$
8 \text { (30) }
$$$$
14(52)
$$$$
5 \text { (18) }
$$

Physician-rated general health

Excellent/good

Fair

Poor/very poor
8 (30)

1 (3.7)
7 (32)

8 (36)
P value

$5(21)$

0.72

$13(54)$

6 (25)

7 (32)

0.007 
Table 4 Cancer-specific geriatric assessment (C-SGA) characteristics in the individual site and total study populations (Continued)

\begin{tabular}{lll}
\hline $\begin{array}{l}\text { Type of treatment } \\
\text { Curative }\end{array}$ & $3(13)$ \\
Palliative & $12(44)$ & $21(87)$ \\
Life expectancy & $15(56)$ & \\
$\quad<1$ year & & $13(54)$ \\
$1-2$ years & $7(30)$ & $7(29)$ \\
$3+$ years & $7(30)$ & $4(17)$ \\
WHO performance score & $9(39)$ & 0.02 \\
0 & & $3(12)$ \\
1 & $16(59)$ & $11(46)$ \\
2 & $7(26)$ & $10(42)$ \\
\hline $\begin{array}{l}\text { C-SGA Cancer-Specific Geriatric Assessment, KSGR Kantonsspital Graubünden KSSG Kantonsspital St. Gallen, SD Standard Deviation, WHO World } \\
\text { Health Organization. } \\
\text { * Test of difference between study sites. }\end{array}$ &
\end{tabular}

\section{Discussion}

This study demonstrated that the SAKK C-SGA is feasible and easy to implement in daily clinical practice. The overall time to complete was less than 30 minutes and considered acceptable by patient and physician alike. Importantly, most participants rated the SAKK C-SGA (patient questionnaire and MRA) as easy or fairly easy to complete. Only a small number of patients or physicians reported questions that were either difficult or unanswered. This likely reflects real-world patient-specific difficulties encountered in daily oncological practice as opposed to problems with the questions themselves. This is supported by the fact that all measures included in the SAKK C-SGA are widely used and previously validated. Plus there was no pattern to the individual questions that were reported as difficult or unanswered (e.g. only one question was mentioned twice, questions identified were not domain-specific).

These findings also suggest that the SAKK C-SGA was able to objectively discriminate older patients' health. The difference in SAKK C-SGA scores between study sites mirrored differences in the site-specific patient characteristics. KSGR had an overall healthier population (as assessed by other health-related measures) with a higher proportion of patients being treated for curative intent than KSSG. Correspondingly, KSGR SAKK CSGA scores were lower and a higher proportion was below the cut-off score (i.e. fit for standard treatment). In both sites more patients below the cut-off score had better physician-rated general health, a longer life expectancy as well as better WHO performance scores. Interestingly, in this population C-SGA scores were related to other health measures but not age, underscoring the potential advantage of C-SGA versus age-based decision-making. As expected (i.e. health-related measures were designed to assess unique health states) there was not complete overlap in how individual health-related measures and the SAKK C-SGA identified the patient population. This is similar to findings by other researchers who found physicians and C-SGA do not identify the same patient populations as fit/unfit for treatment and that C-SGA compares with but is not identical to assessments based other health-measures [36-40].

Although shorter screening tools exist and the SAKK C-SGA had high correlation with other simpler healthrelated measures (e.g. WHO performance score) it affords additional clinical benefit to patient and provider [4,25,40-44]. The time to complete though longer than a brief screen is suitable for pre-treatment or pre-trial oncological work-ups. The time to complete the SAKK C-SGA in daily oncological practice was similar to that of another C-SGA tool pilot tested in clinical trial settings [25]. It also requires much less time and no referral for a full comprehensive geriatric assessment. This is particularly important since not all healthcare systems offer specialized geriatric care. Second, the SAKK C-SGA identifies individual domain deficits for intervention acknowledged within the C-SGA literature as having specific benefits in the care of older cancer patients $[2,16,19,45]$. The problems identified can be addressed either within oncological practices and/or by referral depending on available resources and expertise. For example, engaging social workers, arranging transportation, or providing nutritional counseling before start of treatment could be arranged by staff handling cancer treatment, general practitioners, or referral to a geriatrician depending on individual patient needs and care situations.

The key advantage is that such interventions, regardless of where they are initiated, may mitigate an older patient's risk for poor cancer treatment outcomes and 
increase their quality of life. A recent study in Spain showed that C-SGA detects more information than oncological evaluation alone [46]. Another in Canada found that in $70 \%$ of their study patients C-SGA identified previously unidentified medical problems [47]. In this Swiss population, over half of our patients were identified by the SAKK C-SGA as not a risk for poor outcomes (i.e. below cut-off/fit for standard treatment). Nevertheless, all but one of these patients had a deficit in at least one domain that otherwise may not have been identified by oncological evaluation alone or even a briefer C-SGA screen. Thus use of the SAKK C-SGA provides readily usable information that can improve outcomes for patients above or below the cut-off without delay (i.e. no additional assessment necessarily required). However, we did find that when dementia was present the SAKK C-SGA (like any geriatric assessment) was challenging to administer. In patients with dementia (especially advanced cases) decision-making regarding treating cancer is likely not be aided by objective C-SGA measurement. But instead will require a more complex individualized process between patient-physician-family/ caregiver.

Other researchers in the field and SIOG have identified the need for shorter C-SGA tools applicable for busy clinical oncology settings [48]. The SAKK C-SGA has several benefits directly addressing this need. First, assessment using the SAKK C-SGA requires much less time than a full geriatric assessment and does not require referral to a specialist or geriatrics training to administer. Second, using standard geriatric assessment tools in key domains the SAKK C-SGA maximizes information gathering and minimizes patient/physician burden. In fact, since the tool can be administered by any combination of patient (all but Mini-Cog), trained staff, or physician it is easily customized to the individual patient and clinical setting. Lastly, our findings suggest that use of the SAKK CSGA is feasible in clinical practice and may be well suited to determine eligibility for clinical trials based on patient health instead of chronological age.

A major challenge of C-SGA is to find a balance between time to conduct and producing clinically useful information (i.e. identifying targets for intervention). The SAKK C-SGA is a step forward in this balancing act but can be further improved. This study used an electronic excel-based CCI calculator that made collecting comorbidity data and calculating CCI information easier, more accurate, and immediately available [28]. Based on our positive experience with the excel-based CCI we decided that an electronic version of the SAKK C-SGA could offer similar advantages in clinical practice and clinical trials. An electronic SAKK C-SGA would make gathering data more efficient, produce real time results that can be immediately incorporated into treatment planning, and increase the likelihood of more widespread and uniform use. Development is underway and validation and feasibility studies are planned.

Several strengths and weaknesses of this study should be considered. The SAKK C-SGA was developed with input from geriatricians and oncologists specifically for use in busy oncological and clinical trial settings. The tool includes only standard psychometrically evaluated geriatric assessment measures covering previously identified key domains. The SAKK C-SGA is easy to score and available in multiple languages. However, the results of this study are based on a small number of patients in Switzerland. Thus generalizability of these findings to other clinical settings and other healthcare systems are limited. We did not require exact measurement of time to complete and assume that most patients/physicians estimated times. However, both the patient and physician estimates had similar standard deviations and the perception of time to complete (i.e. estimated time was acceptable to nearly all) is an important factor in willingness to adopt the tool. The SAKK C-SGA should be further tested in larger patient samples, a variety of settings, and over longer periods of time to include outcome data.

\section{Conclusions}

In conclusion, these results suggest that the SAKK CSGA is a promising tool for use in clinical practice. It demonstrated discriminative ability based on objective geriatric assessment measures. It also provides important clinical information that could be used for interventions aimed at optimizing outcomes in older cancer patients. Future studies of SAKK C-SGA reliability, discriminative ability for clinical decision-making based on treatment outcomes, accuracy predicting cancer-related outcomes, ability to improve outcomes, and generalizability are warranted.

\section{Additional file}

Additional file 1: Detailed contents of the SAKK Cancer-Specific Geriatric Assessment (C-SGA).

\section{Abbreviations}

CCl: Charlson comorbidy index; C-SGA: Cancer-specific geriatric assessment; GDS: Geriatric depression scale; IRB: Institutional review board; KSGR: Kantonspital graubünden; KSSG: Kantonspital St. Gallen; mMOSSS: Modified medical outcomes study -social support survey; MNA: Mini nutritional assessment; MRA: Medical record abstraction;

SAKK: Schweizerische arbeitsgemeinschaft für klinische krebsforschung; SIOG: International society of geriatric oncology; VES: Vulnerable elders survey; WHO: World Health Organization.

\section{Competing interests}

None of the authors have a conflict of interest. The sponsors had no role in the design, methods, subject recruitment, data collection, analysis, or paper preparation 


\section{Authors' contributions}

All authors made substantial contributions to this work as follows: study design- KC, PB, FH, UM. Data collection- RC, MF, GR, FH, UM. Data analysisLN, AS, KC. Interpretation of data- all; manuscript preparation and approval of drafts and final submitted version- all.

\section{Acknowledgement}

We are grateful to the practitioners and participants involved in this study. This work was supported by funds from the Swiss Group for Clinical Cancer Research [38/08].

\section{Author details}

'Institute of Social and Preventive Medicine (ISPM), University of Bern, Finkenhubelweg 11, Bern CH-3012, Switzerland. ${ }^{2}$ Section of Geriatrics, Boston University School of Medicine, Boston Medical Center, Boston, MA, USA. ${ }^{3}$ Division of Geriatrics, Department of General Internal Medicine, Inselspital University Hospital and University of Bern, Bern, Switzerland. ${ }^{4}$ Swiss Group for Clinical Cancer Research, SAKK Coordinating Centre, Bern, Switzerland.

${ }^{5}$ Kantonsspital Graubünden, Chur, Switzerland. ${ }^{6}$ Oncology-Haematology Department, Kantonsspital St. Gallen, St. Gallen, Switzerland. ${ }^{7}$ Department of Internal Medicine, Hematology, Medical Oncology, and Pneumology, University Medical Center of the Johannes Gutenberg University, Mainz, Germany.

Received: 10 April 2013 Accepted: 14 August 2013

Published: 23 August 2013

\section{References}

1. World Health Organization: Cancer. Fact sheet 297. Geneva, Switzerland: WHO; 2013. http://www.who.int/mediacentre/factsheets/fs297/en/index. html.

2. Balducci L, Colloca G, Cesari M, Gambassi G: Assessment and treatment of elderly patients with cancer. Surg Oncol 2010, 19(3):117-123.

3. Macleod U, Mitchell ED, Burgess C, et al: Risk factors for delayed presentation and referral of symptomatic cancer: evidence for common cancers. Br J Cancer 2009, 101(Suppl 2):S92-S101.

4. Hurria A, Lichtman SM, Gardes J, et al: Identifying vulnerable older adults with cancer: integrating geriatric assessment into oncology practice. J Am Geriatr Soc 2007, 55:1604-1608.

5. Huss A, Stuck AE, Rubenstein LZ, et al: Multidimensional preventive home visit programs for community-dwelling older adults: a systematic review and meta-analysis of randomized controlled trials. J Gerontol A Biol Sci Med Sci 2008, 63:298-307.

6. Wieland D, Ferrucci L: Multidimensional geriatric assessment: back to the future. J Gerontol A Biol Sci Med Sci 2008, 63:272-274.

7. Ellis $G$, Whitehead MA, Robinson $D$, et al: Comprehensive geriatric assessment for older adults admitted to hospital: meta-analysis of randomised controlled trials. BMJ 2011, 343:d6553.

8. Brunello A, Sandri R, Extermann M: Multidimensional geriatric evaluation for older cancer patients as a clinical and research tool. Cancer Treat Rev 2009, 35:487-492.

9. Balducci L: New paradigms for treating elderly patients with cancer: the comprehensive geriatric assessment and guidelines for supportive care. J Support Oncol 2003, 1:30-37.

10. Chen CC, Kenefick AL, Tang ST, McCorkle R: Utilization of comprehensive geriatric assessment in cancer patients. Crit Rev Oncol Hematol 2004, 49:53-67.

11. Clough-Gorr KM, Stuck AE, Thwin SS, Silliman RA: Older breast cancer survivors: geriatric assessment domains are associated with poor tolerance of treatment adverse effects and predict mortality over 7 years of follow-up. J Clin Oncol 2010, 28:380-386.

12. Caillet $\mathrm{P}$, Canoui-Poitrine F, Vouriot J, et al: Comprehensive geriatric assessment in the decision-making process in elderly patients with cancer: ELCAPA study. J Clin Oncol 2011, 29:3636-3642.

13. Liu JJ, Extermann M: Comprehensive geriatric assessment and its clinical impact in oncology. Clin Geriatr Med 2012, 28:19-31.

14. Clough-Gorr KM, Thwin SS, Stuck AE, Silliman RA: Examining five- and ten-year survival in older women with breast cancer using cancer-specific geriatric assessment. Eur J Cancer 2012, 48:805-812.
15. Puts MT, Hardt J, Monette J, et al: Use of geriatric assessment for older adults in the oncology setting: a systematic review. J Natl Cancer Inst 2012, 104:1133-1163.

16. Extermann $M$, Aapro $M$, Bernabei $R$, et al: Use of comprehensive geriatric assessment in older cancer patients: recommendations from the task force on CGA of the International Society of Geriatric Oncology (SIOG). Crit Rev Oncol Hematol 2005, 55:241-252.

17. Pallis $A G$, Fortpied C, Wedding $U$, et al: EORTC elderly task force position paper: approach to the older cancer patient. Eur J Cancer 2010, 46:1502-1513.

18. Cohen HJ: The cancer aging interface: a research agenda. J Clin Oncol 2007, 25:1945-1948

19. Maas HA, Janssen-Heijnen ML, Olde Rikkert MG, Machteld Wymenga AN: Comprehensive geriatric assessment and its clinical impact in oncology. Eur J Cancer 2007, 43:2161-2169.

20. Balducci L, Extermann M: A practical approach to the older patient with cancer. Curr Probl Cancer 2001, 25:6-76.

21. Roche RJ, Forman WB, Rhyne RL: Formal geriatric assessment, an imperative for the older person with cancer. Cancer Pract 1997, 5:81-86.

22. Extermann M: Basic assessment of the older cancer patient. Curr Treat Options Oncol 2011, 12:276-285.

23. Soubeyran P, Fonck M, Blanc-Bisson C, et al: Predictors of early death risk in older patients treated with first-line chemotherapy for cancer. J Clin Oncol 2012, 30:1829-1834.

24. Aparicio T, Jouve JL, Teillet $L$, et al: Geriatric factors predict chemotherapy feasibility: ancillary results of FFCD 2001-02 phase III study in first-line chemotherapy for metastatic colorectal cancer in elderly patients. J Clin Oncol 2013, 31:1464-1470.

25. Hurria $A$, Cirrincione $C T$, Muss $H B$, et al: Implementing a geriatric assessment in cooperative group clinical cancer trials: CALGB 360401. J Clin Oncol 2011, 29:1290-1296.

26. Falandry C, Brain E, Bonnefoy M, Mefti F, Jovenin N, Rigal O, Guillem O, E Kouri C, Uwer L, Abadie-Lacourtoisie $S$, et al: Impact of geriatric risk factors on pegylated liposomal doxorubicin tolerance and efficacy in elderly metastatic breast cancer patients: Final results of the DOGMES multicentre GINECO trial. Fur I Cancer 2013, 49(13):2806-2814.

27. Charlson ME, Pompei P, Ales KL, Mackenzie CR: A new method of classifying prognostic comorbidity in longitudinal studies: development and validation. J Chronic Dis 1987, 40:373-383.

28. Hall WH, Ramachandran R, Narayan S, et al: An electronic application for rapidly calculating Charlson comorbidity score. BMC Cancer 2004, 4:94.

29. Saliba D, Elliott M, Rubenstein LZ, et al: The Vulnerable Elders Survey: a tool for identifying vulnerable older people in the community. J Am Geriatr Soc 2001, 49:1691-1699.

30. Rinaldi $P$, Mecocci $P$, Benedetti $C$, et al: Validation of the five-item geriatric depression scale in elderly subjects in three different settings. $J \mathrm{Am}$ Geriatr Soc 2003, 51:694-698.

31. Vellas B, Villars $H$, Abellan $G$, et al: Overview of the MNA-Its history and challenges. J Nutr Health Aging 2006, 10:456-463. discussion 463-455.

32. Borson S, Scanlan JM, Chen P, Ganguli M: The Mini-Cog as a screen for dementia: validation in a population-based sample. J Am Geriatr Soc 2003, 51:1451-1454.

33. Moser A, Stuck AE, Silliman RA, et al: The 8-item modified medical outcomes study social support survey (mMOS-SS): psychometric evaluation shows excellent performance. J Clin Epidemiol 2012. in press.

34. McDowell I: Measuring health: A guide to rating scales and questionnaires. New York, NY: Oxford University Press; 2006.

35. Oken MM, Creech RH, Tormey DC, et al: Toxicity and response criteria of the eastern cooperative oncology group. Am J Clin Oncol 1982, 5:649-655.

36. Wedding U, Kodding D, Pientka L, et al: Physicians' judgement and comprehensive geriatric assessment (CGA) select different patients as fit for chemotherapy. Crit Rev Oncol Hematol 2007, 64:1-9.

37. Tucci A, Ferrari S, Bottelli C, et al: A comprehensive geriatric assessment is more effective than clinical judgment to identify elderly diffuse large cell lymphoma patients who benefit from aggressive therapy. Cancer 2009, 115:4547-4553.

38. Luciani A, Ascione G, Bertuzzi C, et al: Detecting disabilities in older patients with cancer: comparison between comprehensive geriatric assessment and vulnerable elders survey-13. J Clin Oncol 2010, 28:2046-2050 
39. Mohile SG, Bylow K, Dale W, et al: A pilot study of the vulnerable elders survey-13 compared with the comprehensive geriatric assessment for identifying disability in older patients with prostate cancer who receive androgen ablation. Cancer 2007, 109:802-810.

40. Owusu C, Koroukian SM, Schluchter M, et al: Screening older cancer patients for a comprehensive geriatric assessment: a comparison of three instruments. J Geriatr Oncol 2011, 2:121-129.

41. Overcash JA, Beckstead J, Moody L, et al: The abbreviated comprehensive geriatric assessment (aCGA) for use in the older cancer patient as a prescreen: scoring and interpretation. Crit Rev Oncol Hematol 2006, 59:205-210.

42. Molina-Garrido MJ, Guillen-Ponce C: Development of a cancer-specific comprehensive geriatric assessment in a University Hospital in Spain. Crit Rev Oncol Hematol 2011, 77:148-161.

43. Kellen $E$, Bulens $P$, Deckx $L$, et al: Identifying an accurate pre-screening tool in geriatric oncology. Crit Rev Oncol Hematol 2010, 75:243-248.

44. Bellera CA, Rainfray M, Mathoulin-Pelissier S, et al: Screening older cancer patients: first evaluation of the G-8 geriatric screening tool. Ann Oncol 2012, 23:2166-2172

45. Hurria A: Geriatric assessment in oncology practice. J Am Geriatr Soc 2009, 57(Suppl 2):S246-S249.

46. Girones R, Torregrosa D, Maestu I, et al: Comprehensive geriatric assessment (CGA) of elderly lung cancer patients: a single-center experience. J Geriatr Oncol 2012, 3:98-103.

47. Horgan AM, Leighl NB, Coate L, et al: Impact and feasibility of a comprehensive geriatric assessment in the oncology setting: a pilot study. Am J Clin Oncol 2012, 35:322-328.

48. Balducci L, Extermann M: Cancer and aging. An evolving panorama. Hematol Oncol Clin North Am 2000, 14:1-16.

doi:10.1186/1472-6947-13-93

Cite this article as: Clough-Gorr et al: The SAKK cancer-specific geriatric assessment (C-SGA): a pilot study of a brief tool for clinical decision-making in older cancer patients. BMC Medical Informatics and Decision Making 2013 13:93.

\section{Submit your next manuscript to BioMed Central and take full advantage of:}

- Convenient online submission

- Thorough peer review

- No space constraints or color figure charges

- Immediate publication on acceptance

- Inclusion in PubMed, CAS, Scopus and Google Scholar

- Research which is freely available for redistribution 